se prête tout spécialement à l'arboriculture. Néanmoins, il se trouve entouré d'une zone industrielle. En 1900, la population s'élevait à 189 personnes; en 1953, à 159 personnes! Le nombre des habitants vivant exclusivement des produits du sol a diminué, durant cette période, de $17 \%$, celui des petits paysans travaillant également dans l'industrie de $27 \%$, tandis que celui des ouvriers industriels a augmenté de $44 \%$. C'est la raison pour laquelle de nombreuses fermes furent transformées en demeures ouvrières. Des ouvriers et employés venus de dehors habitent dans une succession de nouvelles maisonnettes familiales.

\title{
ÜBER DIE ZEITLICHE EINORDNUNG DER MORÄNEN „ZÜRICH-PHASE“ IM REUSSGLETSCHERGEBIET
}

\author{
Joseph KNauer
}

Mit 6 Abbildungen

E I N LE IT UNG

Auf Grund der langjährigen Kartierungsarbeiten im südbayerischen Glazialgebiet wurde vom Verfasser (1928, 1929, 1931, 1935 und 1937) nachgewiesen, daß die früher von K. TROLL (1925) als frische Rückzugsmoränen der „Neowürm-Phase“ oder „Ölkofener Phase“ angesehenen Moränenzüge keinesfalls frische Rückzugsmoränen, sondern älterer Entstehung sind und als Vorrückungsmoränen angesehen werden müssen. In den Jahren 1936 und 1937 wurden vom Verfasser die gleichartigen Moränen der sogenannten „Zürich-Phase“ im Linthgletscher-Gebiet der Schweiz untersucht, wobei zahlreiche einwandfreie Beweise beigebracht werden konnten, daß auch im schweizerischen alpinen Vorland die sogenannten „Zürich-Moränen“ keine Rückzugsmoränen der Würmeiszeit sind, sondern mindestens an den Anfang der Würmeiszeit gestellt werden müssen, wenn sie nicht sogar in die ausgehende Rißeiszeit gehören, worüber vom Verfasser (1938) ausführlich berichtet wurde. Die damals gewonnenen Ergebnisse ließen es als wahrscheinlich erscheinen, daß diese Alterszuteilung für die Eiszeitgletscher des gesamten nördlichen Alpenvorlandes Geltung haben müsse, so weit nicht störende Faktoren (Relief des Vorlandes, Beeinflussung durch Nachbargletscher usw.) einen anderen Ablauf des Eiszeitgeschehens bedingten. Die geplanten weiteren Untersuchungen im Reußgletscher-Gebiet wurden zunächst durch den Ausbruch des zweiten Weltkrieges verhindert, konnten aber nunmehr mit Unterstützung der Deutschen Forschungsgemeinschaft im Frühjahr 1953 durchgeführt werden, wofür hiemit gebührender Dank ausgesprochen sei.

Die Untersuchungen wurden in der Zeit vom 15. Mai bis 9. Juni 1953 vorgenommen und erstreckten sich über das voralpine Gebiet des diluvialen Reußgletschers, nämlich über die Täler der Jonen, der Reuß, des Baldegger- und Sempachersees und des Rothbachtales (siehe Karte). Die Geländebegehungen erforderten die Zeit von vollen 20 Arbeitstagen.

\section{A LLGEMEINE BEMERKUNGEN}

Im ersten Band seiner «Geologie der Schweiz» spricht Alb. Неim (1919) auf S. 263 von glazialen Erosionsformen, welche aus durch den aufs neue darüber vor. rückenden Gletscher verpflügten und gekämmten Randmoränen gebildet seien; in ihrer Scharung entsprächen sie der Form der ehemaligen Randmoräne. Über die Natur und Bildungsweise von überfahrenen Moränenzügen bestand also für Hегм kein $Z$ weifel. Es erregt daher einige Verwunderung, daß weder Herm noch sonstige Schweizer Geologen die naheliegende Nutzanwendung aus dieser grundsätzlichen Erkenntnis zogen und bei der Gliederung der jungeiszeitlichen Ablagerungen nicht auf die augenfälligen morphologischen Unterschiede der verschiedenen Stadialmoränen achteten, sondern schematisch alle hinter der äußersten Würmmoräne liegenden Stadien als jeweils jünger ansahen, je näher sie dem Alpenrande lagen.

Die grundlegenden Unterschiede zwischen dem jüngeren frischen und vollständig erhaltenen würmeiszeitlichen Komplex und dem älteren Moränenkranz wurden vom Verfasser bereits im Jahre 1938 geschildert ${ }^{1}$.

1 „Während die Moränen der beiden äußeren Stillstandslagen gewöhnlich unruhige und unregelmäßig grubige Oberflächen-Formen aufweisen, besitzen die Moränen der Zürich-Phase ausgeglichene, drumloide Formen, die auf eine Verschleifung durch fließendes Gletschereis hinweisen. Außerdem sind sie nur mehr teilweise erhalten, was ihre Erkennung und Verfolgung stellenweise sehr schwierig macht. $\mathrm{Da} \beta$ diese Moränenzüge trotz der morphologischen Besonderheit echte, wenn 


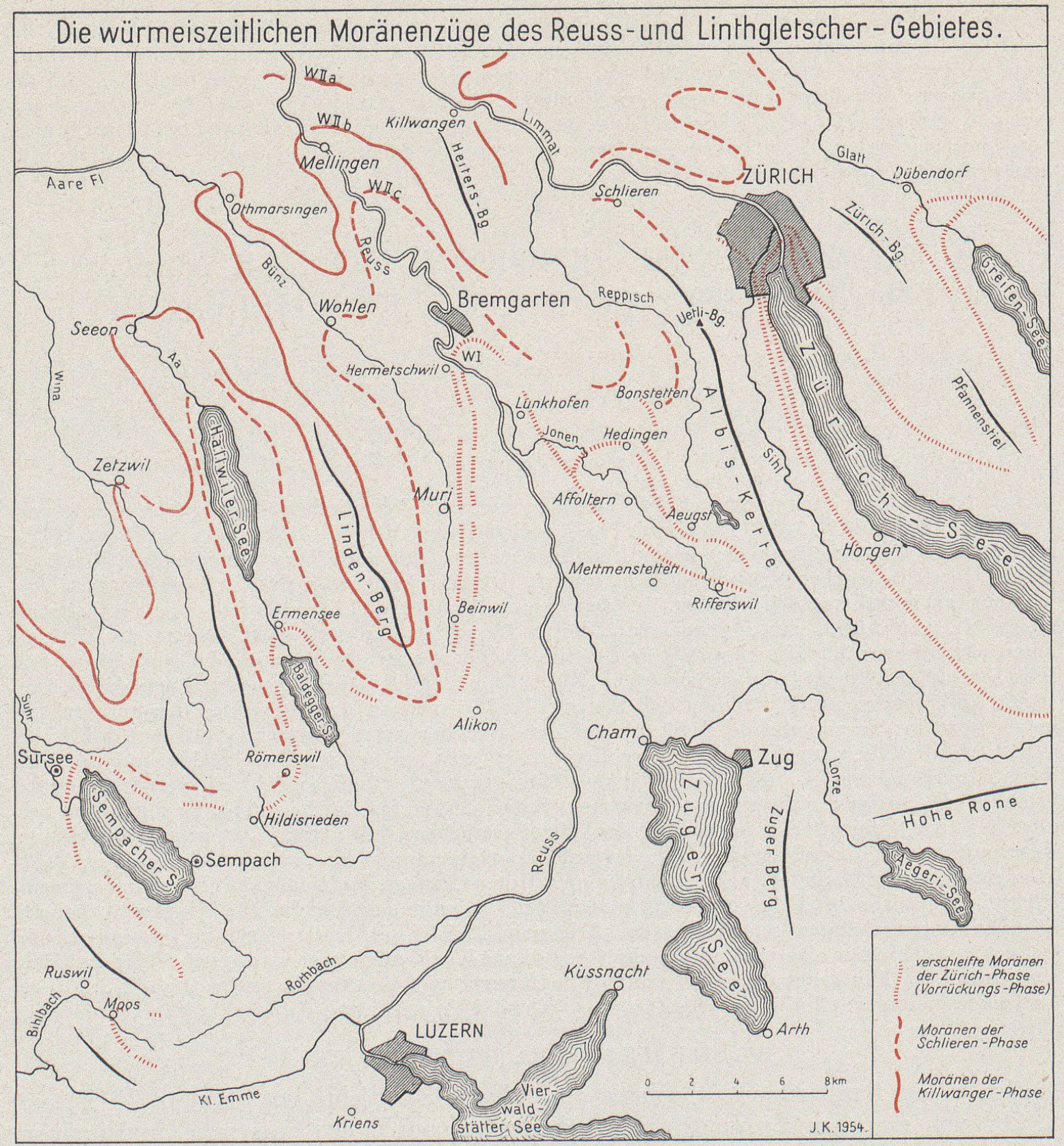

Was damals über die Eiszeit-Ablagerungen des Linthgletschers-Gebietes gesagt wurde, gilt gleicherweise auch für das Reußgletscher-Gebiet.

auch verstümmelte Wallmoränen sind, beweist ihr stratigraphischer Aufbau; denn sie bestehen in ihrem Kern aus echtem Wallmoränen-Schutt. Von besonderer Wichtigkeit aber ist es, daß sie fast immer mit einer wechselnd mächtigen Lage von Grundmoräne überdeckt sind, und zwar nicht nur auf ihrer Innenseite, sondern auch auf ihrem Rücken und auf der Außenseite (Übergangskegel). Dadurch unterscheiden sie sich wesentlich von den frischen Wallmoränen der Killwangen- und Schlieren-Phase, die nur auf ihrer Innenseite in Grundmoräne übergehen, sonst aber frei von einer geschlossenen Grundmoränendecke sind.

Eine weitere Besonderheit der Moränen der Zürich-Phase ist das Fehlen frischer Schotterfluren (Sander), die sich an die Wallmoränen auf der Außenseite anschließen sollten, wie dies ausnahmslos bei den äußeren frischen Moränen von Killwangen und Schlieren der Fall ist. Statt dessen finden sich vielfach feuchte Wiesengründe oder Torfmoore auf der Außenseite der Moränen des Zürich-Stadiums.

Alle diese geschilderten Verhältnisse sind nur erklärlich, wenn man annimmt, daß die Moränen der Zürich-Phase nicht während des Rückzuges der würmeiszeitlichen Vergletscherung abgelagert wurden, sondern daß sie in die Zeit vor der größten Ausdehnung der Gletscher der Würmeiszeit einzureihen sind." 
Abb. 1

Baugrube bei der Emaus-Kapelle.

In der nördlich der Kapelle ausgehobenen Baugrube auf dem Scheitel der Bremgartener Moräne ist die tiefgründig verwitterte lehmige Grundmoräne mit großen Findlingen sichtbar.

Aufnahme J. Knauer

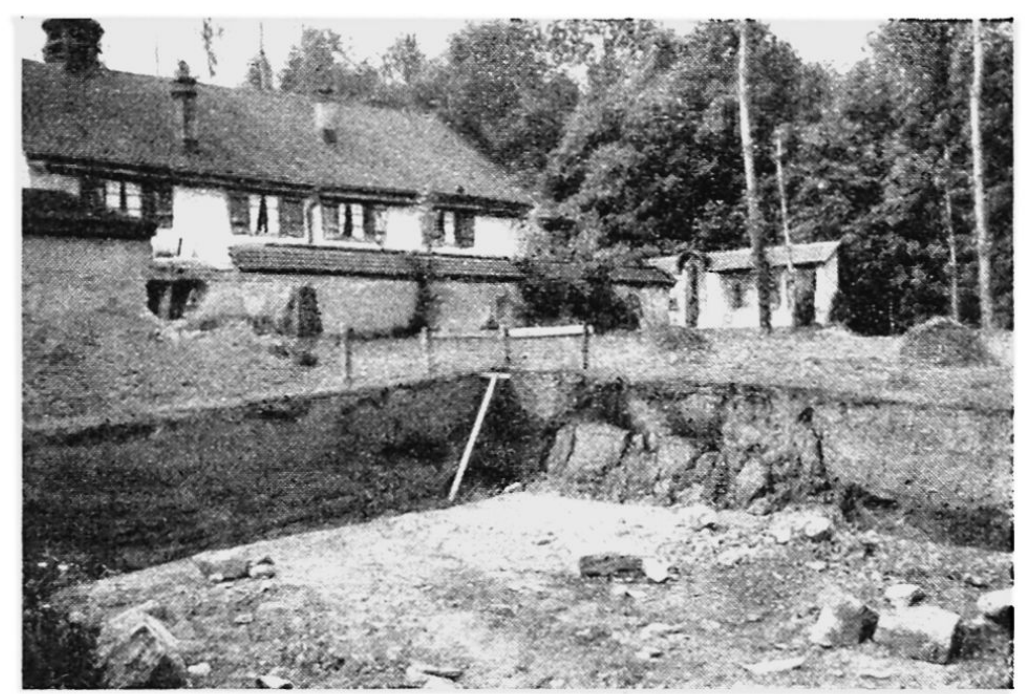

\section{VERBREITUNG UND AUFBAU DER MORÄNEN DER ZÜRICH-PHASE IM BEREICHE DES REUSSGLETSCHERS}

Der diluviale Reußgletscher war während der Zürich-Phase in fünf Lappen gegliedert, nämlich in den Hauptarm des Reußtales und in vier Nebenarme, den östlich gelegenen von Hedingen-Affoltern (Jonengebiet) und. die westlichen $Z_{\text {weigbecken }}$ von Baldegg, Sempach und das Rothbachtal. Die Endmoränen in diesen fünf Becken liegen nach den Angaben der Geologischen Generalkarte der Schweiz 1:200 000, Bl. 2 Basel-Bern und Bl. 3 Zürich-Glarus bei Hedingen, Bremgarten, Ermensee, Sursee und südöstlich von Ruswil. Auch im Geologischen Atlas der Schweiz 1:25 000, Bl. 186-189 Beromünster-Hochdorf-Sempach-Eschenbach von KoPP (1945) ist die Lage der Zürich-Moränen eindeutig festgelegt. Nachstehend-sollen nun die Ergebnisse der Untersuchungen über den Verlauf, den stratigraphischen Aufbau und die Formengestaltung der Ablagerungen der Zürich-Phase geschildert werden.

\section{Die Ablagerungen der Zürich-Phase im Reußtal und im Hedinger Zweigbecken}

Die größte Ausdehnung erreichte der diluviale Gletscher der Zürich-Phase im Stammbecken der Reuß; deshalb sollen sich nachstehende Ausführungen zunächst mit diesem Gebiet befassen.

Die Stirnmoräne bei Bremgarten. - Etwa $1 \mathrm{~km}$ südlich der Stadt Bremgarten (Bl. 157, 668/244) ${ }^{1}$ überquert nach allen bisherigen Angaben die Stirnmoräne das Reußtal (siehe die Karte auf Seite 72). Schon beim Betrachten des Atlasblattes 157 (Bremgarten) fällt sofort auf, daß dieser Stirnmoränenbogen keine frische Wallmoräne mit steiler Innenseite und flacher Außenseite (Übergangskegel) sein kann, sondern daß es sich um ganz flache überschliffene Hügel handeln muß. Es war schon vor der Geländeuntersuchung für den Verfasser klar, daß hier auf der Oberfläche dieser rundgebuckelten Hügel keine Schottermoräne, sondern nur Grundmoräne erwartet werden konnte, welche Erwartung sich auch tatsächlich erfüllte; denn ein glücklicher Zufall fügte es, daß sowohl in Zufikon (669/244) als auch bei der EmausKapelle (668/244) Baugruben geöffnet waren, welche einen Einblick in den Aufbau dieser Stirnmoräne gewährten. Etwa $3 / 4 \mathrm{~km}$ südôstlich von Bremgarten bei Sentenzelg (westlich von Zufikon) waren auf dem abgeflachten Querrücken der Stirnmoräne zwei Baugruben ausgehoben, deren eine neben der Straße Bremgarten-Zug, deren andere etwa $40 \mathrm{~m}$ östlich der Straße lag. In letzterer Grube war eine 1,0-1,2 m mächtige gelblichbraune lehmige Grundmoräne mit Geschieben über dem Moränenschotter sichtbar aufgeschlossen. In der Baugrube neben der erwähnten Strảße war eine Grund-

${ }^{1}$ Die Ziffern beziehen sich auf die Blätter des Topographischen Atlasses der Schwei\% 1:25000 und deren Koordinaten. 


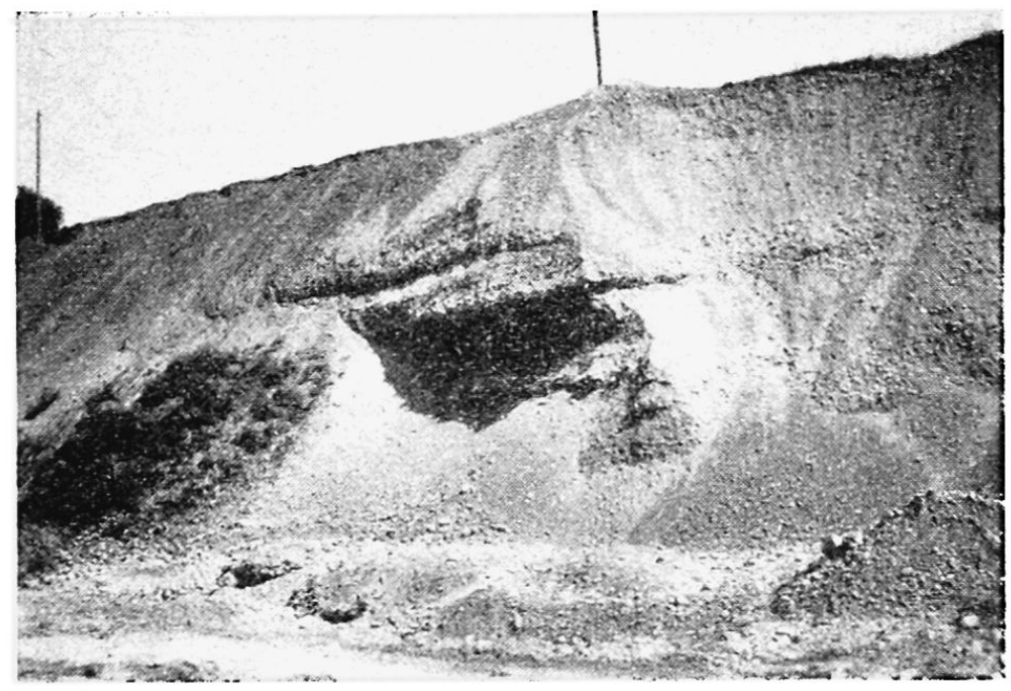

Abb. 2

Schottergrube westlich von Bremgarten.

Der dem Sander der Bremgartener Moräne zugehörende Schotter enthält eine etwa $1 \mathrm{~m}$ mächtige Konglomeratbank, welche auf dem Bilde deutlich hervortritt.

Aufnahme J. Knauer

moräne gleicher Art von 2,0-2,5 m Mächtigkeit zu sehen. Bemerkenswert ist, daß diese Baugruben sich weder auf der Innenseite noch auf dem Scheitel der Moräne befanden, sondern etwa $80 \mathrm{~m}$ nördlich der Kammlinie auf dem Übergangskegel der Außenseite, wo auf allen frischen Wallmoränen nur Moränenschotter, aber keine Grundmoräne zu finden ist. Das gleiche Bild bot sich etwa $300 \mathrm{~m}$ westlich bei der Emaus-Kapelle, wo nördlich der Kapelle ebenfalls eine Baugrube ausgehoben war (Abb. 1), in welcher die tiefgründig verwitterte Grundmoräne mit großen Granitfindlingen etwa 1,5-2,0 m mächtig zu sehen war. Ferner war an der Böschung der Straße, welche zum Elektrizitätswerk an der Reuß hinabführt, die Überlagerung der Zürich-Moräne durch tiefgründig verwitterte Grundmoräne sehr gut sichtbar aufgeschlossen. Diese Aufschlüsse, die sich über die ganze Länge der Stirnmoräne erstreckten, zeigen, daß es sich dabei um eine allgemeine und wesentliche Eigenschaft dieser Moräne handelt, wodurch sie sich von allen übrigen Moränenzügen der Würmeiszeit unterscheidet.

Das fluvioglaziale Schotterfeld im Reußtal. - An die Bremgartener Stirnmoräne sollte sich nun ein frisches fluvioglaziales Schotterfeld anschließen, wenn sie eine junge und ungestörte Rückzugsmoräne wäre. Wohl ist das Reußtal unterhalb Bremgarten mit Schmelzschottern reichlich erfüllt, aber sie sind ebensowenig jung und frisch, wie die Bremgartener Stirnmoräne selbst, und sie zeigen wie letztere eine Beeinflussung durch den darüber hinweggeflossenen Gletscher der würmzeitlichen Hauptvereisung, deren Endmoränen weiter talabwärts liegen. Zahlreiche und ausgedehnte Gruben geben einen lehrreichen Einblick in den Aufbau dieser Schotterfüllung des Reußtales. In Bremgarten auf dem linken Hochufer der Reuß beiderseits der Straße BremgartenWohlen (667/244-245) befinden sich ausgedehnte Schottergruben, in denen diese mächtigen Schotter abgebaut werden. In der westlich der Straße gelegenen Grube sind die Schotter in einer Mächtigkeit von etwa $10 \mathrm{~m}$ aufgeschlossen. Im südlichen Teil der Grube war an der östlichen Abbauwand der sehr grobe Schotter etwa 4-5 m unter der Oberkante zu einem festen Konglomerat verbacken (Abb. 2) ; die Konglomeratbank hat eine Mächtigkeit von etwa $1 \mathrm{~m}$. An der westlichen Abbauwand sah man auf dem groben Schotter etwa $1 \mathrm{~m}$ mächtige Grundmoräne ausgebreitet. Der Schotterkomplex ruht auf Grundmoränenmaterial, das nach Angaben des Besitzers nach unten in steinfreien sandigen Schlick übergeht. Letzterer gehört vermutlich in die Riß-Würm-Interglazialzeit.

In der Kiesgrube östlich der Straße sind die groben Schotter in einer Mächtigkeit von rund $18 \mathrm{~m}$ aufgeschlossen und gut geschichtet; die Größe der Gerölle kann bis Kopfgröße erreichen, was darauf schließen läßt, daß die Schotter in Moränennähe abgelagert sein müssen; dies gilt mindestens für den oberen Teil des Komplexes. Im 
Abb. 3

Schottergrube bei Niederwil

In den gut geschichteten Schottern, die zum Sander der Bremgartener Moräne gehören, ist in der Mitte der Abbauwand eine ausgeprägte Flexur zu sehen, welche steil gegen rechts $(\mathrm{N})$ einfällt; an ihr ist die rechte Scholle um etwa $2-3 \mathrm{~m}$ durch den Eisdruck abgesenkt worden.

Aufnahme J. Knauer

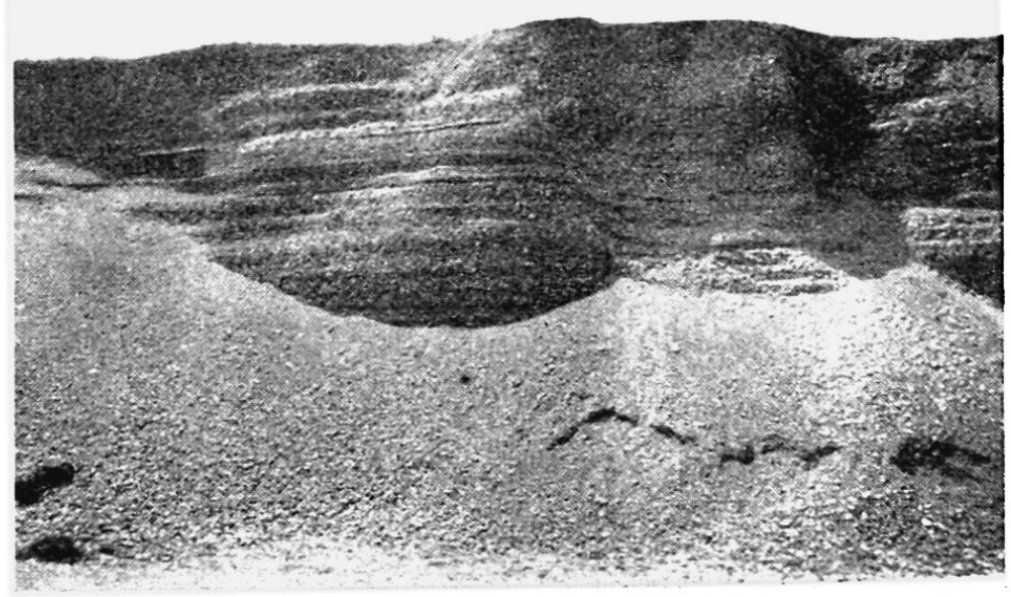

nördlichen Teil der Grube ist die Lagerung der Schotter gestört, indem die sonst wagrechten Schichten durch den Eisdruck in eine weitgespannte flache Mulde zusammengestaucht sind. Im südlichen Teil der Grube war am oberen Rande der Abbauwand die Überdeckung mit einer etwa $2 \mathrm{~m}$ mächtigen Grundmoräne sichtbar, welche in einer flachen Wanne der Schotteroberfläche eingelagert war. Wie in der vorbesprochenen Grube kommen auch hier konglomerierte Lagen im Schotter vor, von denen große Blöcke auf der Sohle der Grube herumliegen. Das Liegende der Schotter wird von interglazialem sandigem Seeschlick gebildet.

Außer der Moränenüberdeckung und der gestörten Lagerung der Schichten ist das Vorkommen von Nagelfluhbildungen von besonderem Interesse. Erfahrungsgemäß ist die Konglomeratbildung in würmeiszeitlichen Schottern eine große Seltenheit und an besondere Umstände gebunden, z. B. Austritt von Grundwasser aus dem Schotter, wodurch eine örtliche Versinterung der Schotter herbeigeführt werden kann. Aber eine bankweise Konglomerierung in größerer Ausdehnung inmitten der Schotter, wie sie in den vorbeschriebenen Kiesgruben vorliegt, kommt nur in älteren, also vorwürmzeitlichen Schottern vor. Auch aus diesem Grunde können diese das Reußtal erfüllenden Schotter keine würmzeitlichen Rückzugsschotter sein, sondern gehören mindestens in den Anfang der Würmeiszeit als Schmelzschotter der Vorrückungsphase. $\mathrm{Da}$ aber während der Interglazialzeit und beim Vorrücken des Gletschers aus den Alpen bereits Schotter aufgeschüttet wurden (die sogenannten Älteren Würmschotter), die dann vom Eise wieder überschritten wurden, so ist anzunehmen, daß der tiefere Teil dieser Reußtal-Schotter zu den Vorrückungs-Schottern gehört. Beim Stationärwerden des Gletschers bei Bremgarten während der Zürich-Phase ging dann die Aufschotterung außerhalb der Stirnmoräne ohne Unterbrechung weiter, weshalb es nicht möglich ist, diese ältesten Vorrückungs-Schotter, die den tiefsten Teil des Komplexes bilden, von den darüber liegenden Schottern der Zürich-Phase abzugrenzen. Der unter dem Schotter liegende sandige Seeschlick kann nach Lage der Sache spätrißzeitlich bezw. interglazial sein.

Etwa $4 \mathrm{~km}$ nordwestlich von Bremgarten befindet sich zwischen Niederwil und Nesselnbach (Bl. 155, 664/248) westlich der Hauptstraße eine Grube in den gut geschichteten Reußtal-Schottern, in denen außer einigen welligen Verbiegungen der Schichten auch zwei ausgeprägte Flexuren zu sehen waren, an denen die jeweils nördlichen Teile des Schotters etwa 2 bis $3 \mathrm{~m}$ durch den Eisdruck abgesenkt waren (Abb. 3). An einer Stelle konnte auch in einer grubenartigen Vertiefung der Schotteroberfläche Überlagerung durch Grundmoräne festgestellt werden.

Ganz besonders eindrucksvoll waren die Aufschlüsse in der ausgedehnten Kiesgrube östlich der Hauptstraße bei Nesselnbach (664/249). An der über $100 \mathrm{~m}$ langen 
westlichen Abbauwand der Grube war die durch Eisdruck verursachte Lagerungsstörung der im übrigen gut geschichteten Schotter deutlich zu sehen. Am nördlichen Ende der Grube konnte man feststellen, wie die flach gegen Westen einfallenden Schotterschichten am östlichen Abhang des Geländes sozusagen in die Luft ausstreichen; denn hier wurden sie vom darüber hinweg gegangenen Gletscher abgeschürft, welch letzterer die ehemalige ebene Schotterfläche in eine flachwellige Landschaft umgestaltet hat. Die Überdeckung des Schotters mit bis zu $3 \mathrm{~m}$ mächtiger Grundmoräne ist in der ganzen Ausdehnung der Grube zu sehen.

Aus dem bisher Gesagten ist zu entnehmen, daß sich im Reußtal an die überfahrene Moräne der Zürich-Phase kein unversehrtes fluvioglaziales Schotterfeld anschließt, wie es der Fall sein müßte, wenn die Bremgartener Moräne die jüngste Rückzugsmoräne wäre, wie man bisher annahm. Statt dessen liegt eine flachwellige Landschaft vor, die aus der ursprünglich ebenen Schotterfläche herausmodelliert wurde. Der Beweis für diesen Vorgang ist in der überall feststellbaren Überdeckung des Schotterfeldes durch Grundmoräne zu sehen. In diese flachwellige Schotterlandschaft hat sich nach dem Rückzug des Eises die Reuß ihre heutige Flußrinne eingetieft.

Die rechte Seitenmoräne. - An die Stirnmoräne bei Bremgarten schließt sich bei Ober-Zufikon die rechte Seitenmoräne an, die einige langgestreckte drumloid geformte sanfte Hügelrücken kennzeichnen. An der Außenseite der bewaldeten Hügel findet sich aber kein Schotterfeld, wie man erwarten sollte, sondern ein leicht wannenförmig eingesenkter Talboden ohne Abfluß zum Bremgartener Schotterfeld. Der Boden dieser Wanne ist vermutlich mit Grundmoräne bedeckt, da das vom «Hardt 》Steilhang herabkommende Rinnsal nicht im Talboden versickert, wie es der Fall sein müßte, wenn dieser ein frisches Schotterfeld wäre. Dagegen überquert das Rinnsal den Talboden und bricht in einem mehrere Meter tiefen Graben quer durch die verschleifte Seitenmoräne. In diesem Graben ist die Grundmoräne mit Findlingen durchsetzt sichtbar aufgeschlossen. Diese verschleifte Moräne ist in südöstlicher Richtung bis etwa zur Flurbezeichnung «Thalacker» (Bl. 157, 670/242) zu verfolgen, wo sie am Hang ausläuft. Es folgt dann eine Unterbrechung von etwa $2 \mathrm{~km}$ und erst nordöstlich von Ober-Lunkofen (Bl. 171, 672/241) beginnt bei P. 506 im «Bannwald» ein flach gewölbter Hügelrücken, der die Fortsetzung der rechten Seitenmoräne bilden und sich in südöstlicher Richtung etwa $1,5 \mathrm{~km}$ weit verfolgen läßt (siehe Karte). Die Straße von Ober-Lunkofen nach Arni überquert diesen Moränenzug bei P. 516 (Bl. 174, 672/240) in einem tiefen Einschnitt. Südlich davon war auf dem Scheitel des flachen Moränenrückens ein Wasserbehälter gebaut worden, dessen Aushub aus sandig-lettiger Grundmoräne mit geschrammten Geschieben bestand. Die Oberfläche des Moränenrückens ist sehr sanft gewölbt und auf der Außenseite der Moräne schließt sich kein Schotterfeld an, sondern nur eine flachwellige Verebnung, welche vermutlich ebenfalls mit einem Grundmoränenschleier überzogen ist, da sie von einigen Rinnsalen durchzogen ist, deren Wasser nicht versickert. Dieser verschleifte Moränenrücken endet etwas östlich von Litzi, wo er durch das postglaziale Jonen-Tal unterbrochen ist (s. Karte). Seine Fortsetzung südlich dieses Tales schart sich dann bei Bärenstudweid $(673,74 / 239)$ mit der Seitenmoräne des Gletscherlappens, der sich zur Hedinger Stirnmoräne ausstülpte. Auch letztere Moräne ist keine frische Rückzugsmoräne, sondern ist von der Würmhauptvereisung überschliffen worden. Ebenso wie die Bremgartener Moräne ist auch die Hedinger Moräne mit einer starken lettigen Grundmoränendecke überzogen, wie in einer Baugrube auf dem Scheitel der Moräne zu sehen war; letztere war in etwa $2 \mathrm{~m}$ Mächtigkeit aufgeschlossen. Außerdem fehlt auch hier im anschließenden $Z$ weigbecken das dazu gehörende Schotterfeld; statt dessen sind ausgedehnte Moorgründe auf dem Talgrund bis zur Stirnmoräne von Bonstetten vorhanden. 


\section{Abb. 4}

Verschleifte Wallmoräne bei Großholz.

Das Bild zeigt den drumloid geformten Hügelzug der verschleiften Wallmoräne der Zürich-Plıase.

Aufnahme J. Knauer

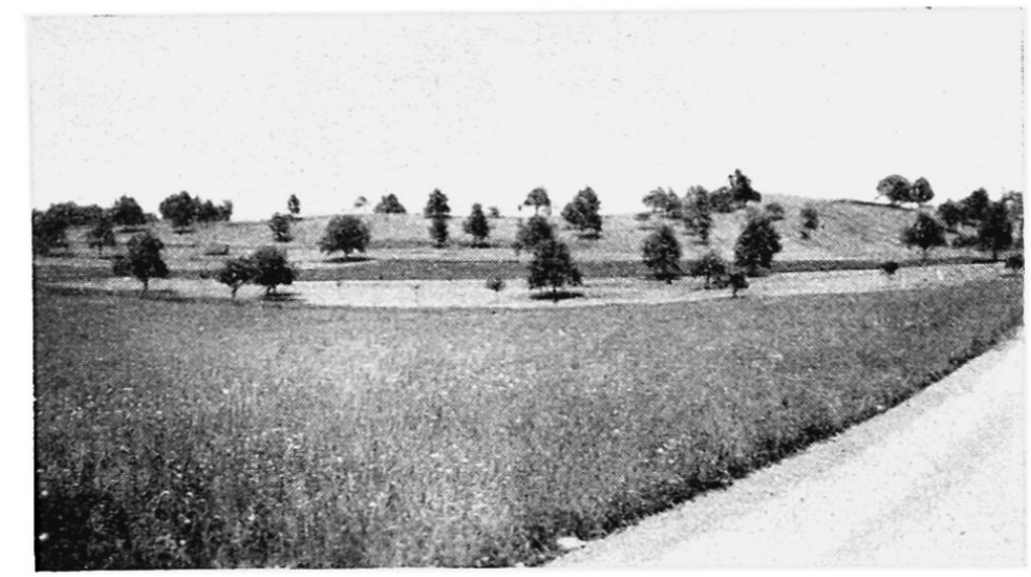

An die Hedinger Stirnmoräne schließt sich die rechte Seitenmoräne an, deren Verlauf HUg (1907) auf S. 134 schilderte ${ }^{2}$. Ebenso wie die Hedinger Stirn- und Seitenmoräne sieht Hug auch die Stirnmoräne von Bonstetten (677/241) als eine Rückzugsmoräne an (s. Karte). Die Bonstettener Moräne ist aber ein zweifelhaftes Gebilde; ihr Kern scheint ein vorwürmzeitlicher Deltaschotter zu sein, der in einer großen Schottergrube am Nordwestabfall der Moräne in ziemlicher Mächtigkeit aufgeschlossen ist. Das Delta ist von einer etwa $2 \mathrm{~m}$ mächtigen Grund- und Schottermoräne bedeckt, so daß also der Gletscher der Hauptvereisung darüber hinweggegangen zu sein scheint. Auch die sich daran anschließende rechte Seitenmoräne ist nur in einzelnen Resten vorhanden; dazu können die Höhén P. 627 « Hirslenhau » (östlich von Hedingen) und P. 642 «ohlenholz» (nördlich der Straße von Affoltern nach Mühleberg) gerechnet werden. Auch bei Äugst (Bl. 176, 679/235) ist die angebliche Bonstettener Seitenmoräne nur andeutungsweise vorhanden. Von dem Vorhandensein frischer Rückzugsmoränen kann hier aber keine Rede sein. Die Moränenzüge sind ohne $Z$ weifel vorhanden, aber nur verstümmelt und meist mit Grundmoräne überkleidet. Eine Ausnahme fand sich in einer Schottergrube an der Straßenkreuzung südlich von Äugst (679/235), in welcher die Moränenschotter der Hedinger Seitenmoräne zufällig ohne die sonst regelmäßige Grundmoränenbedeckung aufgeschlossen war.

Sehr bemerkenswert ist, daß in dem Gebiet sowohl östlich der Hedinger als auch der Bonstettener Seitenmoräne keinerlei frische Schotterfelder ausgebreitet sind, die von den Schmelzwässern hätten abgelagert sein müssen. Dagegen sind zahlreiche und zum Teil sehr ausgedehnte Moorgebiete weit verbreitet, wie z. T. das Feldenmoos östlich von Hedingen und das Tegermoos westlich von Mühleberg; in letzterem konnte ich in einer im Bau befindlichen ausgedehnten Dränungsanlage nur lettige Grundmoräne mit Findlingen feststellen. Diese der Hauptwürmeiszeit zugehörige Grundmoräne, welche das ganze Gelände überzieht, hat die Bildung der zahlreichen Möser ermöglicht.

Ungefähr parallel zur Hedinger Seitenmoräne erstreckt sich westlich davon in einem Abstand von $1-1,5 \mathrm{~km}$ ein weiterer verschleifter Moränenzug, welcher ebenfalls der Zürich-Phase zugerechnet werden muß (s. Karte). Es ist das sogenannte Rückzugsstadium von «Affoltern-Mettmenstetten», wie es Hug (a. a. O. S. 134) bezeichnet und darüber geschrieben hat ${ }^{3}$.

2 „Die Moräne steigt von $520 \mathrm{~m}$ bei Hedingen gegen Affoltern rasch am Hang empor. Die Kurhäuser Lilienberg und Lilienhof sind auf dem steilböschigen Moränenwall angelegt. Der letztere erreichte hier bereits eine Höhe von $600 \mathrm{~m}$, das Gefälle der Eiszunge bis Hedingen berechnet sich daraus auf $40 \%$. Die Seitenmoräne zieht sich hinter dem Wengibad immer noch stark ansteigend dem Hang entlang weiter, um sich zwischen Äugst und Vollenried mit der Moräne der Phase von Bonstetten zu einem geschlossenen Walle zu vereinigen, der das Reppischtal nach oben abschließt."

${ }_{3}$,Während des Rückzugsstadiums von Hedingen bildete der Reußgletscher nur noch eine schwache Ausstülpung in das Bonstettener Tal. Bei der weiteren Zurücknahme dieser vorgescho- 
Der Höhenzug zwischen Zwillikon und Ottenbach findet dann seinen Anschluß an die bereits weiter oben beschriebene Scharung der Moränen südlich des JonenTälchens. Auch dieser Moränenzug gehört keinem Rückzugsstadium an, sondern ist ohne $Z$ weifel der Vorrückungsphase der Würmeiszeit zuzurechnen. Dafür sprechen vor allem morphologische Gründe. Die Hügelzüge sind flach gewölbt und drumloid umgestaltet, ihre Oberfläche ist glatt und ohne die unruhige, grubige Beschaffenheit, wie sie die ungestörten frischen Moränen zu besitzen pflegen. Abb. 4 zeigt die drumloide Form einer verschleiften Moräne bei Großholz. Ein weiterer Beweis für die Umgestaltung ist die Überdeckung mit Grundmoräne. Auf dem Rücken der Moräne bei Großholz war an der Straßenböschung im Hohlweg bei der Ortschaft die verwitterte Grundmoräne mit Geschieben etwa $2 \mathrm{~m}$ mächtig aufgeschlossen. Aber nicht nur die Moräne selbst, sondern auch die östlich des Moränenzuges vorhanden sein sollenden frischen Schotterfelder sind von Grundmoräne überdeckt, wofür auch bei Hug die Beweise zu finden sind 4 .

Diesen Ausführungen ist zu entnehmen, daß die der Zürich-Phase zugehörigen rechten Seitenmoränen im Gebiet von Affoltern und Mettmenstetten in mindestens zwei getrennten Moränenzügen entwickelt sind, wozu sich vielleicht in der Bonstettener Ausstülpung der Gletscherzunge noch ein dritter gesellt, der aber nur in Bruchstücken zu erkennen ist.

Die linke Seitenmoräne. - Die linke Seitenmoräne der Reußtal-Gletscherzunge beginnt unmittelbar S der Ortschaft Hermetswil bezw. Staffeln (Bl. 157, 668/242) als ausgeprägter Doppelwall. Die Verbindung zur Bremgartener Stirnmoräne ist durch die postglaziale Eintiefung der Reuß unterbrochen. Das zwischen den beiden Moränenwällen liegende Moorenthal ist ebenfalls eine postglaziale Talbildung. Der westliche Wall reicht zunächst nur etwa $2 \mathrm{~km}$ weit bis Besenbüren (Bl. 171, 668/ 240 ), setzt sich aber nach einer Unterbrechung von rund $2 \mathrm{~km}$ bei Willematten und Wolfsbühl (668/238) wieder fort und endet etwa 2,5 $\mathrm{km}$ weiter südlich bei $\mathrm{Egg}$ (668/236) östlich von Muri. Der östliche Wall kann etwa $6 \mathrm{~km}$ weit ohne Unterbrechung verfolgt werden; er verläuft $W$ von Rottenschwil (657/240), Althäusern (669/238), Aristau (669,70/237) und Birri (670/236) vorbei bis etwa Thürmeln (669/236). Die Oberfläche dieser Moränenzüge ist wie bei allen Moränen der Zürich-Phase ebenmäßig flach gerundet. Am westlichen Fuße der Moräne war neben der Straße bei P. 449 (668/238) in einer Schottergrube die Überlagerung der Moränenschotter mit mächtiger Grundmoräne zu sehen. Westlich dieser z. T. gedoppelten Seitenmoräne erstrecken sich statt des dazu gehörenden Schotterfeldes ausgedehnte Torfmöser in dem flachen und weiten Bünz-Tal, was auf eine ziemlich lückenlose Überdeckung der Schmelzschotterebene mit Grundmoräne schließen läßt.

benen Eiszunge wurden in der Gegend von Affoltern noch verschiedene lokale Moränenzüge gebildet. Die Hauptmoräne erkennen wir auf weite Strecken hin als einen aus der Landschaft gut hervortretenden Wall, besonders beim ,Großhols' und ,Grüt', $1 \mathrm{~km} \mathrm{~s}$ von Affoltern. Die Fortsetzung streicht hoch über Mettmenstetten beim ,Paradies' vorbei.“ Ferner: „Bei Rifferswil bildet die mächtige Moräne durchwegs die Wasserscheide“ (s. Karte). „Nordwestlich von ,Großholz' bei Affoltern finden wir die Fortsetzung unseres Walles als Grat des Höhenzuges zwischen Zwillikon und Ottenbach."“

${ }^{4}$ Er schreibt (1934) über die Grundwasserfassung bei Heferswil-Rifferswil auf S. 114: „Bei Vorstudien für die Erweiterung der Wasserversorgung Mettmenstetten kam man auf den Grundwasserstrom des Jonentälchens. Eine Lehmdecke (vom Verfasser hervorgehoben!) schließt auch hier nach oben ab.“ Ferner auf S. 116: „Erst da, wo unterhalb Affoltern sich der Talboden erweitert, resp. durch unmittelbare Berührung mit dem Moränenwall die Schmelzwasserbäche neuerdings Schotter zuführen konnten, mußte auch die Grundwasserführung wieder zu ergiebiger Entwicklung kommen. Unter der obligaten Lelmbedeckung (vom Verfasser hervorgehoben!) reicht der Wasser führende Schotter bis zu $-6,7 \mathrm{~m}$, unterbrochen von einer dünnen Lehmschicht." Aus diesen Angaben J. HuG's ist ersichtlich, daß die „obligate“ Lehmschicht, die nichts anderes als die Grundmoräne der Würmhauptvereisung ist, das ganze Gebiet überdeckt. Eine solche Erscheinung gibt es nur im Bereiche der verschleiften Würm-Vorrückungsmoräne, niemals aber auf den frischen Schotterfeldern der Würm-Hauptvereisung. 
Abb. 5

Schottergrube in der Stirnmoräne bei Ermensee.

Auf dem Bilde sieht man die schräg einfallenden geschichteten Moränenschotter auf der Außenseite der überfahrenen Stirnmoräne. Die Schichten sind im obersten Viertel diskordant abgeschnitten und von einer Blocklage bedeckt, welche ihrerseits von ungeschichteter Grundmoräne der WürmHauptvereisung überdeckt ist.

Aufnahme J. Knauer

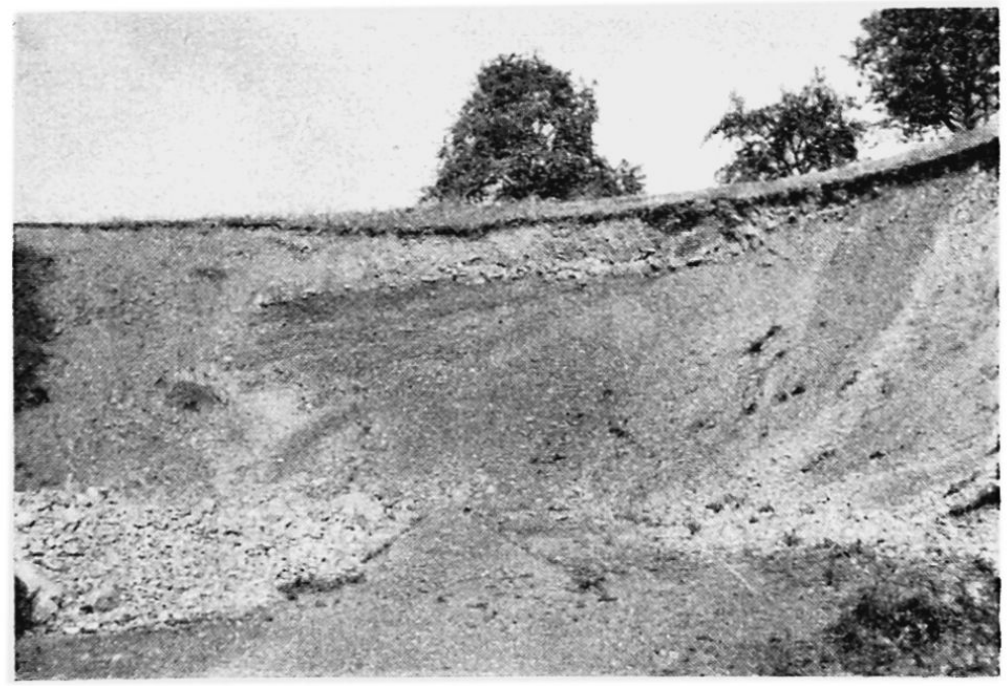

Nach einer Unterbrechung von etwa $1 \mathrm{~km}$ setzt sich der Doppelwall bei Langdorf (Bl. 173, 668/235) wieder fort; der westliche Wall läßt sich hier ununterbrochen bis südlich Beinwil (668/231) verfolgen, während der östliche Wall in drumloide Hügelrücken aufgelöst ist, deren südlichste Ausläufer bei Haldenbühl südwestlich von Ober-Alikon (Bl. 187, 669/227) zu finden sind. Damit endet bezeichnenderweise die westliche Seitenmoräne der Zürich-Phase im Reußtal. Der Südabfall des Lindenbergs ist frei von diesen Moränen und erst im Baldegger $Z$ weigbecken setzen sie wieder ein (s. Karte). Das Fehlen der Moränenzüge auf der Südabdachung des Lindenberges wäre unerklärlich, wenn die Zürichmoränen junge Rückzugsmoränen wären; irgend eine Spur von ihnen müßte doch vorhanden sein; denn es wäre nicht anzunehmen, daß gerade in diesem Gebiet alle Moränen der postglazialen Erosion zum Opfer gefallen sein sollten, während sie an den Talflanken erhalten blieben. Dagegen ist. es begreiflich, daß der Gletscher des Hochstandes der Würmvereisung hier an der Stoßstelle, wo er sich in zwei Äste gabelte, alle vorher gebildeten Moränenzüge abschürfte, so daß heute auf weite Erstreckung hin der Molasseuntergrund zu Tage tritt, wie die Geologische Karte von Kopp (1945) erkennen läßt. Der Südabhang des Lindenberges ist ein Gegenstück zum Südostabfall des Pfannenstielrükkens im Zürichseegebiet, wo die Zürichmoränen vom Gletscher des Würmhochstandes ebenfalls abgeschürft wurden ( $s$. Karte), wie Verfasser früher schon (1938, S. 12) darlegte.

\section{Die Ablagerungen der Zürich-Phase im Zweigbecken des Baldegger-Sees}

Die Stirnmoräne bei Ermensee. - Auf der glazialgeologischen Übersichtskarte (Spezialkarte 1 am Seitenrand) der Geologischen Karte von KopP (1945) umsäumen die Moränen der Zürich-Phase das Becken des Baldegger-Sees. Am Nordrande des Sees bei Ermensee (Bl. 172, 660/231,32) schließt die Stirnmoräne südlich der Ortschaft das Becken ab (s. Karte). Aber es ist keine frische Wallmoräne, die sich quer über das Tal erstreckt, sondern es sind nur mehrere flachgewölbte drumloide Rücken ohne Zusammenhang. Nur der westlichste Moränenhügel, der den Ansatz zur linken Seitenmoräne bildet, aber sich nicht in eine solche fortsetzt, erhebt sich stattlicher aus der Ebene. Auf seiner Westseite befindet sich eine Kiesgrube (s. Abb. 5 ), in welcher der Aufbau dieser Moräne sehr gut studiert werden konnte. Hier war im unteren Teil der Grube der schwach nordwärts fallende Moränenschotter der Zürich-Phase gut aufgeschlossen. Diskordant darüber und die obersten Lagen des Schotters abschneidend befand sich eine etwa $1 / 2 \mathrm{~m}$ mächtige Blocklage und darüber ungeschichtete Grundmoräne, welche bereits dem Hochstande der Würmvereisung angehört. 
Das an die Ermenseer Stirnmoräne sich anschließende Schotterfeld ist wohl vorhanden, aber es muß mit Grundmoränen überkleidet sein; denn die zahlreichen von den Talhängen herabkommenden Rinnsale versickern nicht auf dieser Fläche, wie es bei frischen Schotterfeldern der Fall sein müßte, sondern fließen obertags zum Aabach oder in den nördlich anschließenden Hallwiler See ab. Auch diese Tatsache spricht für ein frühwürmzeitliches Alter dieser Ablagerungen.

Die rechte Seitenmoräne. - Die Entwicklung und der Erhaltungszustand der rechten Seitenmoräne auf dem rechten Talhang des Baldegger Seebeckens ist ziemlich dürftig. Zwischen dem rechten Ende der Stirnmoräne bei der Ruine Grünenberg (661/230) und den drumloiden Hügelrücken bei Gelfingen (B1. 176, 662,63/229) klafft eine Lücke von fast $1 \mathrm{~km}$ Länge. Auch der weitere Verlauf dieser verschleiften Seitenmoräne ist nur andeutungsweise in drumloiden Hügeln zu erkennen, die sich bis Hinteraugstholz östlich von Kleinwangen (Bl. 187, 664/227) erstrecken, wo sie ihr Ende finden, da am Südabfall des Lindenberges die Moränen durch den Gletscher des Würmhochstandes abgeschürft sind, wie weiter oben schon geschildert wurde. In Hinteraugstholz ist die stark gestörte und mit Grundmoräne überdeckte Zürich-Moräne sehr gut aufgeschlossen gewesen. Es ist bemerkenswert, daß diese Moränenreste auch von KoPP (1945) teils als «gerundete Moränenwälle », teils als Drumlins in seiner Geologischen Karte eingezeichnet sind.

Oberhalb dieser Moränen der Zürich-Phase finden sich nun einige Wallmoränenzüge, die sich von Schloß Heidegg (Bl. 185, 663/229) nach Lieli (Bl. 187, 665/ $228)$, Ibenmoos (666/228) und Gölpi (666/227) bis fast nach Holderstock (668/226) hinauf erstrecken. Diese Moränen schließen aber nicht an die Stirnmoräne von Ermensee an; denn sie liegen viel zu hoch über dem heutigen Talgrund. Außerdem haben sie, wie die Moräne beim Schloß Heidegg zeigt, eine viel zu unruhige Oberflächengestaltung, wie es bei frischen Würmmoränen die Regel ist. Es ist bemerkenswert, daß in der Geologischen Karte von KopP diese Moränen auf längere Erstrekkung hin als «einseitig abfallende Moränenwälle» bezeichnet sind. Diese Form findet sich bei den überfahrenen Moränen der Zürich-Phase niemals, außer sie sind einseitig durch Gletscherschurf erodiert worden. Es spricht also auch die Morphologie tatsächlich für ein jüngeres Alter der Heidegger Moräne, die man als Rückzugsmoräne des Schlieren-Stadiums ansehen muß.

Die linke Seitenmoräne. -- Ebenso spärlich wie die rechte Seitenmoräne ist am westlichen Talhang des Baldegger Seebeckens die linke Seitenmoräne der ZürichPhase entwickelt. Es sind nur einzelne drumloide Rücken, welche - mit Unterbrechungen - den Verlauf der Vorrückungsmoräne erkennen lassen, und zwar nordwestlich von Stäffligen (660/229), nordöstlich von Guggerbühl (660/228), westlich von Retschwil (661/227), bei Vorderalp (661/226) und nordöstlich von Römerswil (661/224). Südlich dieser Ortschaft schwenken diese drumloiden Moränenrücken allmählich nach SW und W um, wo sie nördlich von Hildisrieden (Bl. 188, 660/ 222) am Rande der Hochfläche zunächst aussetzen. Auf dem die beiden Seegebiete (Baldegger und Sempacher See) trennenden Molasserücken hat der Gletscher der Hauptwürmeiszeit die älteren Moränenzüge größtenteils abgeschürft, wie es auf allen diesen Molassespornen der Fall ist. In der Geologischen Karte von Kopp sind auch auf dem linken Talhang verschiedene Moränenzüge als «Moränen zwischen Schlieren- und Zürich-Stadium » eingezeichnet ; sie entsprechen der Heidegger Moräne und ihrer Fortsetzung auf der rechten Talseite. Sie sind sicher jünger als die verschleiften Moränen und gehören vermutlich der Schlieren-Phase an. Zu diesen wirklichen Rückzugsmoränen gehört auch diejenige von Gormund (659/223), welche nördlich der Züricher Moränenreste durchzieht und schon morphologisch als jüngere Moräne $\mathrm{zu}$ erkennen ist ${ }^{5}$. Das Gormunder Torfmoos konnte sich nur auf Grund-

5 Kopp (1945) schreibt auf S. 11 seiner Erläuterungen zu der Geologischen Karte : „Zwischen dem Gormunder Wall u. dem oberen Wall des Zürich-Stadiums liegt e Gormund ein ausgedehntes Torfmoos." 
moräne der Würm-Haupevereisung bilden. Wäre die Zürich-Moräne eine Rückzugsmoräne, dann würde sich hier statt des Torfmooses ein Schotterfeld finden, das von den Schmelzwässern der Moräne aufgeschüttet worden wäre.

\section{Die Ablagerungen der Zürich-Phase im Zweigbecken des Sempacher Sees}

Die Moränen der Zürich-Phase umsäumen nach den vorhandenen geologischen Karten von Kopp und der Generalkarte der Schweiz 1:200000 das Becken des Sempacher Sees.

Die Stirnmoräne bei Sursee. - Das Nordwestende des Sempacher Sees bei Sursee (B1. 183, 650,51/225,26) ist von einem ausgeprägten und ausnahmsweise gut erhaltenen Endmoränenkranz umsäumt (s. Karte), so daß man fast versucht sein könnte, diese Wallmoräne tatsächlich als frische Rückzugsmoräne zu betrachten. Wenn man aber im anschließenden Übergangskegel bezw. Schotterfeld verschiedene alte und größtenteils verwachsene Gruben untersucht, läßt sich erkennen, daß die Schotterebene mit mächtigem steinigem Lehm (verwitterte Grundmoräne) bedeckt ist, in welchem größere Findlingsblöcke eingestreut sind. Die Grundmoränenbedeckung läßt sich aber nicht mit einem frischen Schotterfeld vereinbaren. Dazu kommt noch, daß die Oberfläche der Schotterebene von zahlreichen Rinnsalen durchzogen ist, deren Wasser auf der wasserdichten Grundmoräne fließen. Dies wäre aber auf einer Schotterebene nicht möglich, da das Wasser auf letzterer versickern und dem Grundwasser zufließen würde. Es spricht also alles dafür, daß die Stirnmoräne bei Sursee als Vorrückungsmoräne der Zürich-Phase angesehen werden muß.

Die rechte Seitenmoräne. - Auch im Sempachersee-Gebiet sind die Seitenmoränen der Zürich-Phase nur lückenhaft erhalten. So schließen sich an die Stirnmoräne an ihrem Ostende nach einiger Unterbrechung einzelne unzusammenhängende drumloid umgestaltete Hügelrücken bei Schenkon $(653,54 / 225,26)$ an, die sich dann weiter südöstlich an Kesselacker (Bl. 185, 654/223) vorbei und nach längerer Unterbrechung nördlich von Hundgellen (Bl. 188, 656/223) über P. 713 und P. 724 bis nach Schopfen $(658,223,24)$ erstreckt. Dann folgt wieder eine längere Unterbrechung, bis nordöstlich von Hildisrieden die bereits beschriebenen Reste der linken Seitenmoräne des Baldegger Beckens ansetzen.

Die linke Seitenmoräne. - Ähnlich lückenhaft wie die vorbeschriebene rechte ist auch die linke Seitenmoräne des Sempacher Beckens entwickelt. Es sind ebenfalls drumloid umgestaltete Moränenrücken, welche bei Haselrain südlich von Oberkirch (Bl. 185, 651/223) beginnen und sich westlich an St. Margarethen vorbei bei Steinweid (651/221) erstrecken. Nach längerer Unterbrechung setzen sie sich südlich von Nottwil $(653 / 219,20)$ in einzelnen drumloiden Hügelrücken bei Grundacker (654/218) und bei Wilistadt (B1. 202, 655,56/217) fort, um bei Althüsli (655/216) an der Stoßseite des Gletschers des würmeiszeitlichen Hochstandes am Molassesporn zu enden. Die weitere Fortsetzung findet sich erst in einem drumloiden Rücken etwa $2 \mathrm{~km}$ südlich bei Hunkelen (656/214), der aber bereits den Anschluß an das benachbarte Rothbach- bezw. Bihlbach-Tal vermittelt.

\section{Die Ablagerungen der Zürich-Phase im Rothbach-Tal}

Das äußerste $Z$ weigbecken der linken Flanke des Reußgletschers ist das Tal des Rothbaches, wozu noch ein kleines Stück des Oberlaufes des Bihlbaches gehört (s. Karte). In ihm finden sich südöstlich von Ruswil (Bl. 199, 653/214) einige das Tal überquerende Moränenzüge, welche nach den weiter oben erwähnten Geologischen Karten von KopP und der Geologischen Generalkarte der Zürich-Phase zugerechnet werden. Die ausgeprägteste von ihnen überquert bei Moos das Tal; daneben finden sich noch zwei weitere Stirnmoränen, deren eine zwischen Ruswil und Moos das Tal von Nordosten her einengt, während die andere südöstlich von Moos bei Ober- und Unter-Ziswil (Bl. 202, 655/213) das Tal abriegelt und die Talwasserscheide bildet. 
Es ist möglich, daß dieser letztere tatsächlich einem echten Rückzugshalt angehört. Die Moränen bei Moos sind aber vermutlich zur Gemeinschaft der überfahrenen Moränen zu rechnen. Sehr spärlich ist die dazu gehörende rechte Seitenmoräne erhalten, welche nur in einem Hügelrücken zwischen Ober- und Unterherrenweg (655, 213/214) besteht, dessen Fortsetzung erst 1,4 km weiter ostnordöstlich bei dem weiter oben schon erwähnten Moränenhügel von Hunkelen zu suchen ist.

Etwas ausgeprägter ist die linke Seitenmoräne, welche über Diegringen (Bl. 199, 653/212,13) und Hopfgrüti (654/212) zur Höhe des Molasserückens hinaufzieht, der das Rothbach-Tal von dem nacheiszeitlich ausgefurchten Tal der Kl. Emme scheidet.

\section{DIE FORMENGESTALTUNG DER MORÄNEN DER ZÜRICH-PHASE}

Das Grundsätzliche der Formengestaltung der Moränen der Zürich-Phase wurde vom Verfasser bereits in einer früheren Abhandlung (1938) dargelegt und auch in vorstehenden Ausführungen schon erwähnt. Es ist die Tatsache, daß die Moränen dieser Phase durchwegs Stromlinienform besitzen und häufig in drumloide Hügelgruppen (Drumlins) aufgelöst sind. Letzteres ist besonders im Stammbecken und an den Wurzeln der Zweigbecken der Fall, während im Hauptarm des Reußtales und im Affolterner östlichen Nebenarm langgestreckte Moränenzüge erhalten geblieben sind. Dies ist wohl darauf zurückzuführen, daß in diesem Raume das Eis der WürmHauptvereisung gezwungen war, parallel zu den vorhandenen Seitenmoränen zu fließen, wobei letztere wohl zugerundet, aber nicht zerstückelt wurden. Ein gutes Beispiel für eine verschliffene Wallmoräne ist Abbildung 4, welche den Moränenzug bei Großholz zeigt. Er ist ein verblüffendes Gegenstück zur gleichaltrigen linken Seitenmoräne im Zürichseegebiet bei Harrüti, welche in der früheren Abhandlung des Verfassers (1938) auf Tafel V, Fig. 9, abgebildet ist. Hier wie dort unterliegen diese schön geschwungenen und glatt geschliffenen Hügelrücken der landwirtschaftlichen Bodennutzung, während die unregelmäßig gestalteten und unebenen frischen Moränen der Würm-Hauptvereisung sich mehr für den Forstbetrieb eignen.

Der morphologische Unterschied zwischen überfahrenen und frischen Moränen beschränkt sich aber nicht nur auf die Moränen, sondern er ist auch für die an die Moränen anschließenden Schotterfelder maßgebend. So erstreckt sich nördlich der Bremgartener Moräne im Reußtal kein ebenes Schotterfeld, sondern dieses ist infolge der Überfahrung durch den Gletscher der Würm-Hauptvereisung zerschürft und in eine wellige Ebene umgewandelt worden, wie weiter oben schon bei der Besprechung der großen Schottergrube bei Nesselnbach ausgeführt wurde. Für diese morphologischen Unterschiede der verschiedenen glazialen Komplexe gibt es keine andere Erklärung als die Bearbeitung eines älteren Komplexes durch den Gletscher der würmzeitlichen Hauptvereisung. Es ist auch nicht möglich, diese Erscheinungen mit einem kurzfristigen Vorstoß während einer Rückzugsphase zu erklären; denn die Beeinflussung des Schotterfeldes im Reußtal erstreckt sich bis zu den jungen Moränen der Schlieren-Phase und ist nicht auf einen begrenzten, unmittelbar an die Bremgartener Moräne angrenzenden Bereich beschränkt.

Während der Ausarbeitung vorliegender Abhandlung erhielt Verfasser vom Geographischen Institut der Universität Zürich eine Dissertation von M. STEıN (1948) über die Morphologie des Glatt-Tales zugesandt. Mit diesem Glazialgebiet hatte sich auch Verfasser (1938) beschäftigt. Es ist nun interessant, daß STEIN in diesem Glazialgebiet die morphologischen und stratigraphischen Eigenheiten dieses älteren Glazialkomplexes erkannt hat, ohne allerdings die notwendigen und möglichen weiteren Folgerungen daraus zu ziehen ${ }^{6}$.

${ }^{6}$ So schreibt er auf S. 67 von Moränenwällen innerhalb der äußeren würmzeitlichen Hauptmoränen: „Die dritte Kette von Moränenwällen beginnt im Glattal bei Oberhausen-Hohenstiegeln, südlich Glattbrugg-Opfikon. Die Form der Moräne scheint darauf hinzudeuten, daß diese Wälle 
$\mathrm{Zu}$ diesen drumlinisierten Schotterplateaus gehören auch die Schotterfelder der älteren Glazialkomplexe des Greifensee und Pfäffiker Sees. Bemerkenswert ist auch die der Dissertation beigegebene Geologische Karte, in welcher die Überdeckung des ganzen Glazialkomplexes der Zürich-Phase mit Grundmoräne zu ersehen ist, womit allein schon das höhere Alter des glazialen Komplexes im Glattal bewiesen ist.

\section{ÜBER DIE ALTERSFRAGE DER ZÜRICH-PHASE}

Verfasser hat früher (1938, S. 24) die Frage zur Aussprache gestellt, ob die geschilderten Ablagerungen der Zürich-Phase einer frühwürmzeitlichen Vorrückungsphase oder einer spätrißzeitlichen Rückzugsphase zugerechnet werden müssen. Anlaß zu dieser Fragestellung war die 1937 erschienene Vereisungskurve W. Soergels (1937), welche auf eine Riß III-Vereisung von geringerem Ausmaß als die würmeiszeitliche hinweist. Damit schien eine Möglichkeit gegeben zu sein, die Altersstellung der überfahrenen Moränen einer Klärung näher bringen zu können. Vom Verfasser (1917, S. 14) wurde auf diesen verschleiften Moränen eine Verwitterungsdecke nachgewiesen, welche darauf schließen ließ, da $\beta$ mindestens ein Interstadium zwischen dieser und der Hauptwürmvereisung einzuschalten wäre. Diesem Fund eines Verwitterungshorizontes konnte später A. Micheler (1948) einen weiteren im Gebiet des Wertachgletschers anfügen. $\mathrm{Ob}$ nun die vorgebrachten Indizien für einen selbständigen Vorstoß der Zürich-Phase es erlauben, letztere der Spätrißzeit zuzuordnen, ist natürlich sehr fraglich; denn vor allem ist die Klimakurve mit großer Vorsicht $\mathrm{zu}$ betrachten und kann keinesfalls als unfehlbares Beweismittel benützt werden. Dazu kommt noch, daß - wie von mir schon früher (1938, S. 25) betont wurde - die Moränen und Schotter der Zürich-Phase petrographisch den würmeiszeitlichen Ablagerungen näher stehen als den rißeiszeitlichen; aber auch dieser Gesichtspunkt besitzt nur relativen Wert, wie in der gleichen Abhandlung anschließend dargelegt wurde. Dagegen wurden in einer jüngst erschienenen Gemeinschaftsarbeit von H. Graul und I. Sch ÄFER (1953) besonders von letzterem Autor zahlreiche Tatsachen ins Feld geführt, welche zu beweisen scheinen, daß die Ablagerungen der Zürich-Phase einem selbständigen ersten Würmvorstoß (WI) zugehören; diesem folgte ein Interstadium (Verwitterungshorizonte!) mit nachfolgendem Hauptvorstoß (WII), der mit mehreren Stillstandslagen einen zusammengehörenden Komplex (WIIa, b und c) bildet, wie er in allen großen Gletscherbereichen des alpinen Vorlandes entwickelt ist. Damit scheint die Altersgliederung, wie sie Verfasser in früheren Veröffentlichungen vertrat, wieder zu Recht zu bestehen.

Aus den bisherigen Untersuchungen geht klar hervor, daß die Moränen der Zürich-Phase nicht als jungglaziale Ablagerungen der ausgehenden Würmeiszeit angesehen werden können, sondern daß sie der frühen Würmeiszeit angehören müssen, nachdem ein rißeiszeitliches Alter kaum in Frage kommt. Die vom Verfasser früher (1938, S. 27) zusammengestellte Tabelle, welche die Beziehungen zu den süddeutschen Vergletscherungsgebieten darstellt, ist deshalb hier berichtigt beigefügt.

im Talgrund nachträglich nochmals vom Eis überfahren und abgeflacht wurden. Ihre weitern Teilstücke oberhalb Wallisellen und Dietlikon - Baltenswil-Tagelschwangen-Kindhausen-Gutenswil-Buchholz-Freudwil, und der das Kempttal abschließende Wall unterhalb Fehraltdorf erscheinen in ihrer äußeren Form viel eher drumlinhaft als eigentliche Gletscheranhäufungen. Ihr innerer Bau spricht aber ganz deutlich für Obermoränen, wie denn auch die weitere Fortsetzung am Talhang entlang über Kleingripp-Guggu-Lugeten-Ober-Rick-Vor der Burg-Gehmisholz-Furtholz-Balmerberg - Heidenbühl-Kemptnerwald-Bodenweid-Ringwil-Ober-Berneck gegen Wernetshausen sowohl durch ihr Material, wie ihre Form deutlich den ehemaligen Gletscherrand markieren.“ S. 70 schreibt er bei der Besprechung der verschiedenen Rundformen: „Eine erste Gruppe befindet sich in Zonen, wo die Oberfläche leicht ansteigt. Dazu gehören die Formen im Wasserscheidengebiet an der Seehalde, die große Drumlinlandschaft zwischen Dürnten, Wetzikon und Uster, die drumlinisierten Schotterplateaus in ihrer Fortsetzung bis Kloten, sowie das Gebiet um LindauNürensdorf-Breite-Winterberg. “" 
In ihr sind auch die dem äußersten Würmvorstoß (WIIa) angehörenden Moränenreste im Reußtal eingetragen, die A. PENCK und E. BRüCKNER (1909, S. 498) schilderten; es ist ein $4 \mathrm{~km}$ nördlich von Mellingen auf der Lettenzelg unweit Birmersdorf durchziehender flacher Wall, der unter dem Niederterrassen-Schotter fast begraben ist (s. Karte). Damit stimmt die Entwicklung des Komplexes der Hauptwürmzeit (WII) im Reußtal mit derjenigen im süddeutschen Alpenvorland überein, wie es die Tabelle zeigt, nämlich WI als Würmvorstoß-Phase mit nachfolgendem Interstadium; darauf folgt der Würmhauptvorstoß (WII) mit drei Stillstandslagen ( $a, b$ und $c$ ), und schließlich der Rückzug bezw. Zerfall des Eises bis zum Alpenrand.

$\begin{array}{cccccc}\text { Zeitliche } & \text { Reuß- } & \text { Linth- } & \text { Rhein- } & \text { Wertach- } & \text { Ammer- } \\ \text { see- } & \text { Würm- } & \text { Inn- } & \text { Salzach- } \\ \text { Phasenfolge } & \text { Gletscher } & \text { Gletscher } & \text { Gletscher } & \text { Gletscher } \\ \text { Gletscher } & \text { Gletscher }\end{array}$

\begin{tabular}{|c|c|c|c|c|c|c|c|c|}
\hline $\begin{array}{l}\text { Würm I } \\
\text { (verschleifte } \\
\text { Moränen) }\end{array}$ & $\begin{array}{l}\text { Brem- } \\
\text { garten }\end{array}$ & Zürich & Stein & Hirschzell & $\begin{array}{l}\text { Wesso- } \\
\text { brunn }\end{array}$ & Icking & Ölkofen & Tengling \\
\hline $\begin{array}{l}\text { Würm IIa } \\
\text { (Äußerste } \\
\text { Randlage) }\end{array}$ & Lettenzelg & Neuenhof & $\begin{array}{l}\text { Schaff- } \\
\text { hausen }\end{array}$ & - & Stoffen & $\begin{array}{l}\text { Jetten- } \\
\text { hausen }\end{array}$ & Haag & - \\
\hline $\begin{array}{l}\text { Würm IIb } \\
\text { (Rückzugs- } \\
\text { stillstand) }\end{array}$ & $\begin{array}{c}\text { Mellingen } \\
\text { Othmar- } \\
\text { singen } \\
\text { Seeon }\end{array}$ & $\begin{array}{c}\text { Kill- } \\
\text { wangen }\end{array}$ & $\begin{array}{l}\text { Lang- } \\
\text { wiesen } \\
\text { Paradies }\end{array}$ & Hangeck & Reichling & Śchäftlarn & Kirchseeon & Nunreit \\
\hline $\begin{array}{l}\text { Würm IIc } \\
\text { (Rückzugs- } \\
\text { stillstand) }\end{array}$ & Stetten & Schlieren & $\begin{array}{l}\text { Dießen- } \\
\text { hofen }\end{array}$ & $\begin{array}{l}\text { Wein- } \\
\text { halde }\end{array}$ & $\begin{array}{c}\text { St. } \\
\text { Ottilien }\end{array}$ & $\begin{array}{l}\text { Eben- } \\
\text { hausen }\end{array}$ & Ebersberg & Radegund \\
\hline
\end{tabular}

\section{ZUSAMMENFASSUNG}

Zur Fortsetzung der in den dreißiger Jahren vorgenommenen Untersuchung des glazialen Komplexes der Zürich-Phase im Linthgletscher-Gebiet wurden im Jahre 1953 die diesbezüglichen Ablagerungen im Reußgletscher-Gebiet bearbeitet. Diese finden sich in den Tälern der Reuß und der Jonen, der Seen von Baldegg und Sempach und des Rothbach- bezw. Bihl-Tales.

Im ersten Abschnitt wird auf die morphologischen und stratigraphischen Besonderheiten der Ablagerungen der Zürich-Phase und auf ihre Unterschiede gegenüber den frischen Ablagerungen der Hauptvereisung der Würmeiszeit eingegangen.

Im zweiten Abschnitt werden die Ablagerungen der Zürich-Phase im Hauptbecken und den einzelnen $Z$ weigbecken geschildert.

Der dritte Abschnitt befaßt sich mit der Formengestaltung der diesbezüglichen Ablagerungen.

Im vierten Abschnitt wird die Altersfrage behandelt, wobei die früher (1938) zur Aussprache gestellte Frage einer Zuteilung zu einer rißeiszeitlichen Rückzugsphase berichtigt wird. Diese Berichtigung gründet sich auf anderweitige neueste Untersuchungen im Illergletscher-Gebiet, denen zufolgen die Moränen der ZürichPhase tatsächlich der frühen Würmeiszeit (WI) angehören müssen, worauf nach einem Interstadium der Komplex der würmeiszeitlichen Hauptvereisung (WII) mit mehreren Stillstands-Phasen ( $a, b$ und $c$ ) folgt.

\section{SCHR I FTENVER Z E I CH N IS}

Graul, H. und Schefer, I.: Zur Gliederung der Würmeiszeit im Illergebiet. Geologica Bavarica, Nr. 18, München 1953. - Herm, Alb. : Geologie der Schweiz. Bd. I. Leipzip 1909. - Hug, J.: Die letzte Eiszeit in der Umgebung von Zürich. 1907. - Hug, J. und BeILIck, A.: Die Grundwasserverhältnisse des Kantons Zürich. - Beitr. z. Geol. d. Schweiz. Geotechn. Ser. Hydrol. Lief. 1. Bern 1934. - KNauer, J.: Glazialgeologische Ergebnisse aus dem Isargletschergebiet. - Z. Deutsch. Geol. Ges., 80, Monatsber. 8-10, Berlin 1928. - KNAUER, J.: Erläuterungen zum Teilblatt Landsberg des Blattes München-West (XXVII) der Geognostischen Karte von Bayern 1:100000. Mün- 
chen 1929. - KNAUER, J.: Erläuterungen zum Teilblatt München-Starnberg des Blattes MünchenWest (Nr. XXVII) der Geognostischen Karte von Bayern 1:100000. München 1931. - KNAUER, J.: Die Ablagerungen der älteren Würm-Eiszeit (Vorrückungsphase) im süddeutschen und norddeutschen Vereisungsgebiet. - Abh. Geol. Landesunters. a. Bayr. Oberbergamt, 21, München 1935. - KNAUER, J.: Widerlegung der Einwendungen K. TRoll's gegen die Vorrückungsphase der WürmEiszeit. - Mitt. Geogr. Ges. München, 30, München 1937. - KNAueR, J.: Über das Alter der Moränen der Zürich-Phase im Linthgletscher-Gebiet. - Abh. Geol. Landesunters. a. Bayr. Oberbergamt, 33, München 1938. - Kopp, J.: Geologischer Atlas der Schweiz 1:25000, Blätter 186 Beromünster, 187 Hochdorf, 188 Sempach und 189 Eschenbach, mit Erläuterungen. Bern 1945. - Micheler, A.: Verwitterungshorizont der Würm I-Phase bei Ob im Wertachgletschergebiet. Ber. d. Naturf. Ges. Augsburg, 1948. - Scergel, W.: Die Vereisungskurve. Berlin 1937. - Stein, M.: Morphologie des Glattales. Inaugural-Diss. d. Universität. Zürich 1948.

\section{THE CLASSIFICATION OF THE MORAINES OF THE „ZURICH-PHASE“ IN THE REGION OF THE REUSS GLACIER}

Continuing an investigation of the glacial complex of the Zurich-phase in the area of the Linth glacier, carried out in the thirties, the corresponding deposits of the Reuss glacier were examined in 1953. They are found in the valleys of the Reuß and the Jonen, in those of the lakes of Baldegg and of the Rothbach and Sihl respectively. In the first paragraph the morphological and stratigraphical peculiarities of the deposits of the Zurich-phase are described and set in relation to the more recent deposits of the principal glaciation of the Würm glacial period. In the second paragraph the deposits of the Zurich-phase in the primary basin and the detached branch basins are depicted. The third paragraph is devoted to the shapes of these deposits. In the fourth paragraph the question of age is discussed. The former assignment to a retreating phase of the Riss glacial period is corrected. This correction is based on the newest investigations in the area of the Iller glacier. According to these the moraines of the Zurich-phase actually belong to the former Würm glacial period (W I). After an inter-stage follows the complex of the primary glaciation of the Würm glacial period (W II) with several phases of stagnation ( $a, b$ and $c$ ).

\section{ALTINDIANISCHE FELSZEICHNUNGEN AUS DEN KOLUMBIANISCHEN LLANOS}

\section{August Gansser}

Zu Anfang des Jahres 1942 führte der Verfasser im Gebiete des Guayabero Flusses (Kolumbianische Llanos) geologische Untersuchungen aus und beobachtete bei dieser Gelegenheit indianische Felszeichnungen und Gravierungen ${ }^{1}$. Da die Gegend wenig bekannt ist, war es angebracht, die Funde etwas näher zu studieren.

Leider war es dem Verfasser nicht möglich, die Feldbefunde kurz nach deren Bearbeitung bekannt zu geben. Außerdem verhinderte anderweitiger Auslandsaufenthalt eine Verfolgung der Untersuchungen in Nachbargebieten sowie die nötige Fühlungnahme mit der neueren Literatur. Die vorliegenden Notizen stellen ausschließlich das Tatsachenmaterial der Feldbefunde dar. Da das studierte Material langsamer aber sicherer Zerstörung, einerseits durch Flußerosion bei Hochwasser, anderseits durch zunehmende Überkrustung durch Algen und Flechten unterworfen ist, so war es nötig, so viel als möglich von den noch erhaltenen Zeichnungen zu kopieren und im entsprechenden Maßstabe wiederzugeben. Bei dieser Arbeit beschränkte ich mich auf die am wenigsten bekannten Vorkommen sowie auf die wahrscheinlich noch ganz unbekannten Zeichnungen der Felswände von Lindosa.

Die Felszeichnungen der Wände über den Stromschnellen (Raudal) von San Josè dürften die den Indianern am besten bekannten Vorkommen sein und sind leichter zugänglich für nachfolgende Untersuchungen.

\section{DIE LOKALISIERUNG DER VORKOMMEN} [siehe Kartenskizze]

Alle von mir untersuchten Vorkommen beschränken sich auf den Guayabero Fluß und seine nähere Umgebung. Der Guayabero, der, nach der Vereinigung mit dem Ariari als Guaviare einen

1 Inzwischen bereiste (1949-1950) der französische Forscher Alain Gheerbrant das Gebiet und berichtete verschiedenenorts auch über die Felszeichnungen. Dennoch dürfte den hier publizierten Untersuchungen nicht nur Prioritäts- sondern Originalitätswert zukommen, weil die Aufnahme der Zeichnungen systematisch erfolgte. (Anm. der Red.) 